\title{
Maximum Power Point Tracking for Shaded Photovoltaic Generation Using P\&O Fuzzy Logic Approach
}

\author{
Rajagopal Reddy B \\ Associate Professor, Vardhaman College of Engineering \\ *Corresponding author E-mail: reddy.rajagopal@gmail.com
}

\begin{abstract}
A fuzzy logic based photovoltaic controller for shaded photovoltaic power generation is proposed based on P\&O MPPT method. To obtain stable operation and maximum output, the parameters of fuzzy logic controller is adjusted in real time for various shaded conditions. The performance of proposed method of fuzzy controller is examined and validated using MATLAB/Simulink environment.
\end{abstract}

Keywords: Maximum Power Point, P\&O method, Shaded PV Panel, Fuzzy Logic Controller.

\section{Introduction}

Renewable energy sources have become important part of energy power generation. Eco-friendly nature, sustainability, simplest technology and less maintenance are important features of these Renewable energy sources. But intermittent nature of renewable sources causes the uncertain behavior which promotes the unpredictable output. The possible reasons for uncertainty are angle of inclination of solar panel, sun irradiation and partial shading on the panel etc. It is desirable to operate solar panel to get maximum output which is called maximum power point tracking and hence the efficiency of solar power generations can be improved. The existed result[1],[3],[6] shows performance of in-conductance and Perturbation \& Observation methods and their comparisons are discussed in [6], [7]. In [9] the use of Incremental conductance method is presented. Heuristic methods such as Genetic Algorithm and Revisited Perturbation Frequency are discussed[10],[11] and have problem like local minimum problem and lack of convergence. PID controller based Fuzzy logic controller is introduced in [2]. In this paper $\mathrm{P} \& \mathrm{O}$ based fuzzy logic controller[12] for shaded solar power generation is proposed and implemented. The organization of the paper is given as follows. Modeling of Solar Cell is presented in Section II. Fuzzy logic controller for MPPT are discussed in Section III. MATLAB simulation and corresponding results are discussed in Section IV and Sections V discusses conclusion remarks.

\section{Photovoltaic Cell Model}

The photovoltaic (PV) cell is basically a PN Junction diode which works on photovoltaic effect. When Photon energy that is solar irradiation is stricken on the PV cell, electrons-hole pairs are produced due to incident of photos which acts as a PN junction diode. The Volt-Ampere relationship of a PV cell is given by

$$
I=I_{P}+I_{O}\left(e^{\frac{q V}{n K T}}-1\right)
$$

Here $I_{\mathrm{P}}$ denotes current due to photons and $I_{\mathrm{O}}$ denotes reverse saturation current. Equation (1) is the diode current equation, therefore practical PV cell can be modeled as diode parallel with current source along with series and shunt resistances shown in fig.1.

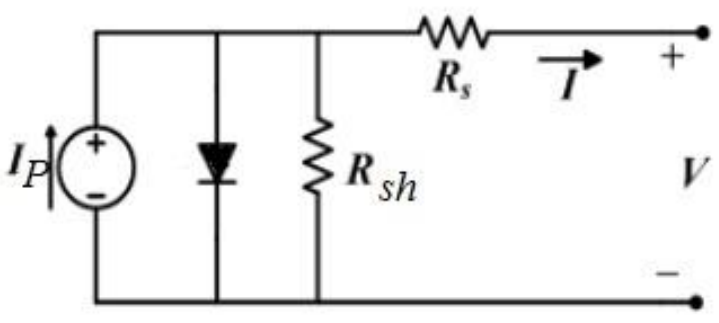

Fig. 1: Electrical equivalent circuit of PV Cell

The series and shunt resistances in fig. 1 are equivalent resistances when PV cell is connected to an external load. The current in equation (1) can be modified after connecting load with series and shunt resistances as

$$
I_{P}+I_{O}\left(e^{\frac{q\left(V+I R_{S}\right)}{n K T}}-1\right)+\left(\frac{V+I R_{S}}{R_{S h}}\right)
$$

Here $I_{P}$ denotes current due to photons, $I_{O}$ denotes reverse saturation current, $\mathrm{R}_{\mathrm{s}} \& \mathrm{R}_{\mathrm{sh}}$ are series and shunt equivalent resistances. 
When photons strike PV cell, initially it carries only photon current $I_{P}$ which is current due to photons and voltage across cell becomes zero at this instant. Therefore the corresponding current is said to be short-circuit current $\mathrm{I}_{\mathrm{sc}}$ and is given by

$$
I_{S C}=I_{P} \text { when } V=0
$$

The photon current $\mathrm{I}_{\mathrm{P}}$ depends on solar irradiation $\mathrm{G}$ in $\mathrm{KW} / \mathrm{m} 2$ and it is proportional solar irradiation. The relation between $\mathrm{I}_{\mathrm{P}}(\mathrm{G})$ and $\mathrm{G}$ is given by

$$
I_{P}(G)=\frac{G}{G_{O}} I_{P}\left(G_{O}\right)
$$

The standard irradiation Go is $1 \mathrm{KW} / \mathrm{m} 2$.

When current starts flowing in PV cell, voltage across cell is developed and this voltage is said to be open-circuit voltage $\mathrm{V}_{\mathrm{oc}}$. This voltage is given by

$$
V_{O C}=\frac{K T}{q} \ln \frac{I_{P}}{I_{O}}
$$

Using $\mathrm{V}_{\mathrm{oc}}$ and $\mathrm{I}_{\mathrm{sc}}$ the characteristics of PV cell can be determined as shown in fig. 2 .

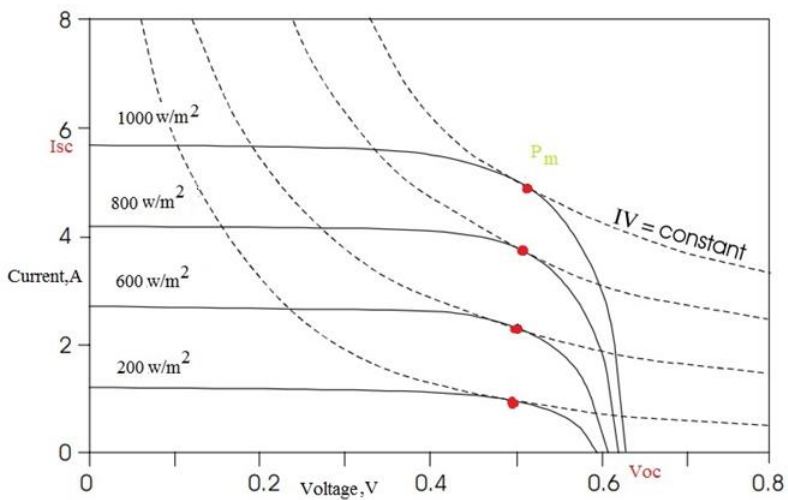

Fig. 2: I-V characteristics of PV Cell

The $I-V$ and $P-V$ characteristics under the different insolation such as $1000 \mathrm{~W} / \boldsymbol{m}^{2}, 800 \mathrm{~W} / \boldsymbol{m}^{2}, 600 \mathrm{~W} / \boldsymbol{m}^{2}$ are shown in fig.3.

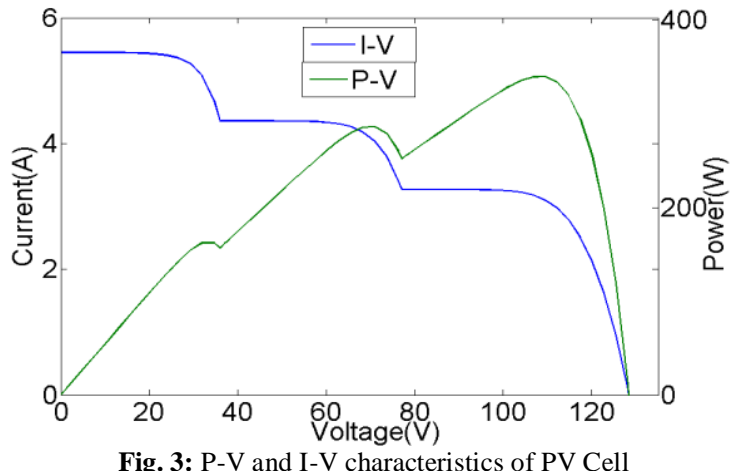

Fig. 3: P-V and I-V characteristics of PV Cell

Photovoltaic (PV) array is arrangement of array of individual PV cells in series and/or parallel combinations. The performance of a such PV array is affected by configuration of array, temperature and insolation. If cells are connected in series then the modules get mismatched that limits the output current, decreases the output power, creates hot-spot in cell may damage the cell. Hence, bypass diode is connected in parallel with module. The PV array consider in this paper consisting of 9 PV modules arranged into three parallels, each having 3 modules connected in series. The simulation diagram is shown in fig. 4 for different cells with partially shaded simulated by different insolation.

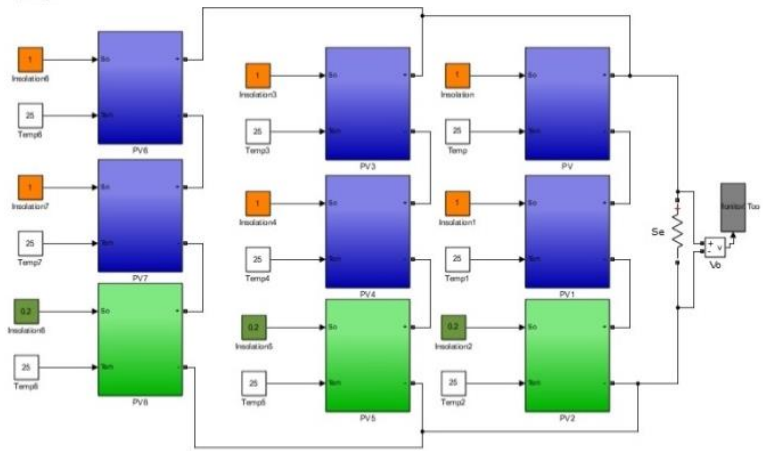

Fig. 4: Arrangement of PV cell to form PV Array

The output power of the PV array is the product of voltage across array and output current and maximum power is given by $\mathrm{P}_{\mathrm{m}}=\mathrm{V}_{\mathrm{m}} \mathrm{I}_{\mathrm{m}}$. Power output depends on solar irradiation, temperature and shadow on PV array. The aim of MPPT is to obtain operational condition to get maximum output power. To achieve this set of hyperbolas can be plotted a set of hyperbolas at IV=constant. The power for corresponding point which is tangent to the cell I$\mathrm{V}$ curve. By finding fist derivative of power equation and setting it to zero, we can obtain maximum power point of the cell. Fig. 5 Shows I-V curves that change with the irradiation of sun. As irradiation increases, the current also increases and corresponding maximum power point moves the upwards. In fig. 5 points A,B are local maximum power points and point $\mathrm{C}$ is the global maximum power point.

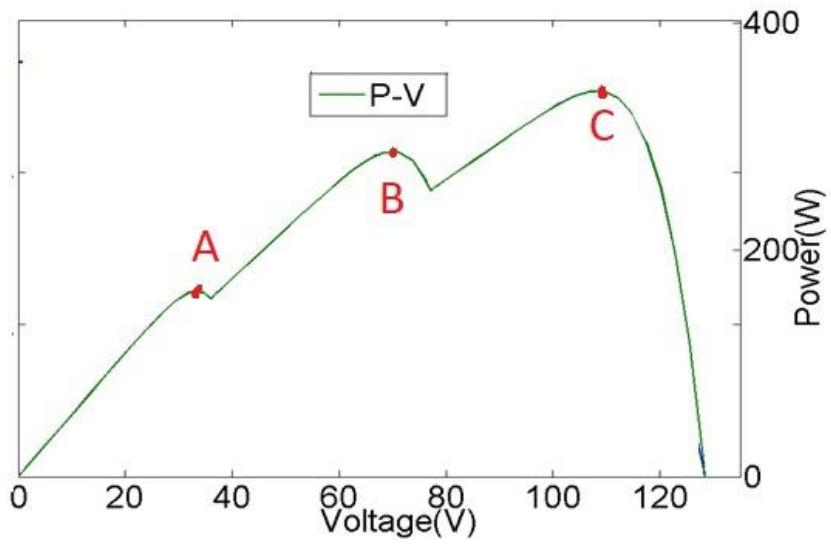

Fig. 5: Maximum power points of PV Array

\section{Fuzzy Logic Controller for MPPT}

\subsection{Proposed Block diagram for MPPT}

The proposed block diagram of $\mathrm{P} \& \mathrm{O}$ fuzzy logic controller for shaded PV generation is shown in fig.6. The output of PV array panel is given to Boost converter. The purpose of this converter is to obtain maximum power point by changing duty cycle. Boost converter is basically DC-DC converter and used to increase output DC voltage levels. The duty cycle is controlled by fuzzy controller which is connected as feedback device as shown in fig.6. The basic circuit diagram of Boost converter is shown in fig.7. MOSFET in the circuit acts as switch. When MOSFET is ON (closed) then inductor gets charged and when it OFF(open) inductor gets discharged and capacitor gets charged. Thus the terminal voltage is controlled by changing duty cycle of switching pulse. 


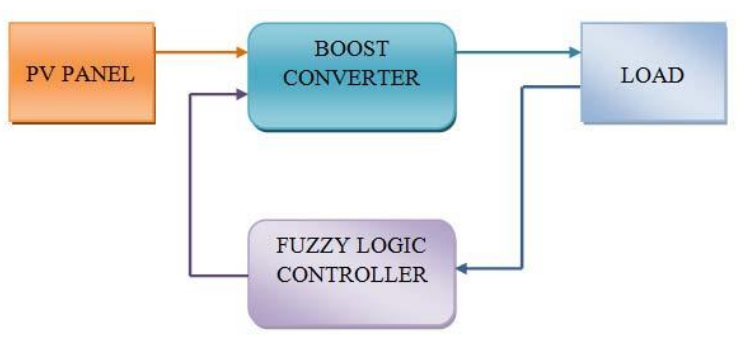

Fig. 6: Schematic diagram of proposed MPPT

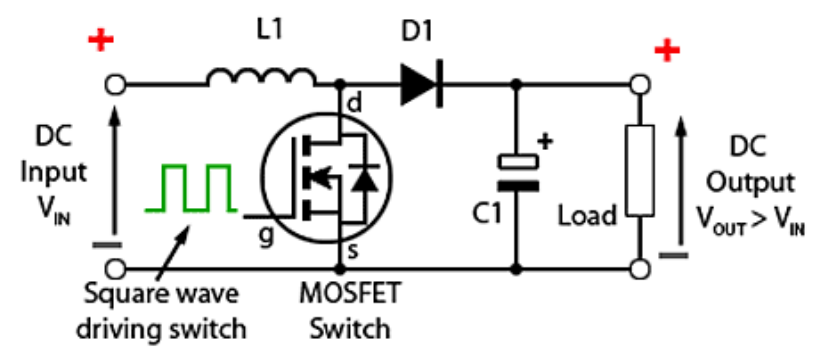

Fig. 7: Boost Converter for MPPT

The concept of fuzzy logic was advanced by Dr. Lotfi Zadeh. Fuzzy logic is a many valued logic and process of fuzzy logic is as follows:

\section{- Fuzzification}

- Rules base

- De-fuzzification

In Fuzzification stage, depends on membership functions, the input numerical variables are converted into linguistic variables or fuzzy variables. In MPPT fuzzy logic controller, error E and derivative of error $d E / d t$ are input variables. Set of rules will be prepared and processed. In the defuzzification stage, depends on membership functions, linguistic variables or fuzzy variables are converted into output numerical variables, which is analog signal used to control Boost converter for MPPT. The advantages fuzzy logic controllers are:

- Work with imprecise inputs

- Work with inaccurate mathematical model

- Handle nonlinearity

Cost of implementation fuzzy logic controller is costly. The process of fuzzy logic controller is visualized in the fig. 8 .

\subsection{P\&O method and Fuzzy logic for MPPT}

The operating condition of the PV array can be altered by $\mathrm{P} \& \mathrm{O}$ method which applies a perturbed voltage $d V$. Previous sampling interval output power and that of the present sampling interval are subsequently compared. Based on these two voltages, MPPT controller can regulate PV array to operate either at higher operating voltage or lower operating voltage. After numerous of iterations, the PV array system will be operated at a particular optimum power point, at which maximum output power will be generated.

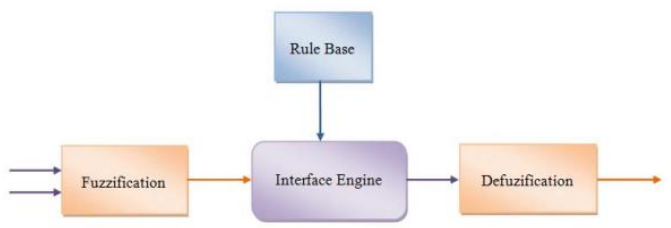

Fig.8 Process of Fuzzy logic controller

The P\&O method algorithm is used to identify maximum power operating voltage, and continually iterate the process for optimal voltage, to track the next maximum power point. This iterative process lead to the problem of power and voltage fluctuations. The fluctuations are more when the perturbation level is high.
Hence fuzzy logic approach is included in the conventional $\mathrm{P} \& \mathrm{O}$ method [3]. The power loss in PV array can be made minimum, by varying the size of perturbation level $\mathrm{dV}$.

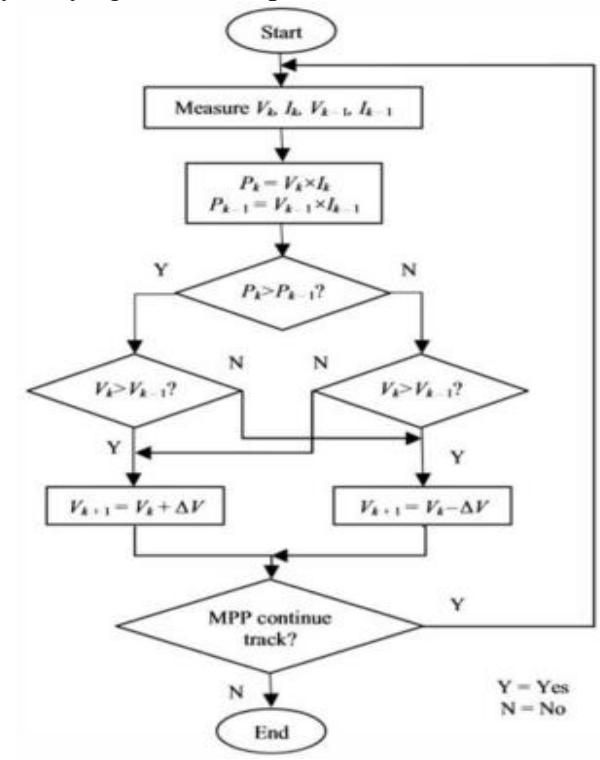

Fig.9 P\&O method flow chart diagram

The membership function of $\mathrm{P} \& \mathrm{O}$ based fuzzy logic has four input variables which are $\mathrm{P}_{\mathrm{k}}, \mathrm{P}_{\mathrm{k}-1}, \mathrm{~V}_{\mathrm{k}}, \mathrm{V}_{\mathrm{k}-1}$ and $\mathrm{V}_{\mathrm{k}+1}$ is the output variable. For each every input/output, unique membership function names should allotted, so that rules for inference engine can be written without any ambiguity. Names of membership functions, its range and fuzzy rules are shown in table1 and table 2 respectively.

Table1: Membership Functions names and range

\begin{tabular}{|c|c|c|c|}
\hline Input & MF & Description & Range \\
\hline \multirow{3}{*}{$\mathbf{P}_{\mathbf{k}}$} & PVL & Power Very Low & {$[0,0.25,0.5]$} \\
\hline & PL & Power Low & {$[0.25,0.5,0.75]$} \\
\hline & $\mathrm{PH}$ & Power High & {$[0.5,0.75,1.0]$} \\
\hline \multirow{3}{*}{$\mathbf{P}_{\mathrm{k}-1}$} & PVLP & $\begin{array}{l}\text { Power Very Low at } \\
\text { Previous condition }\end{array}$ & {$[0,0.25,0.5]$} \\
\hline & PLP & $\begin{array}{l}\text { Power Low Previ- } \\
\text { ous condition }\end{array}$ & {$[0.25,0.5,0.75]$} \\
\hline & PHP & $\begin{array}{l}\text { Power High Previ- } \\
\text { ous condition }\end{array}$ & {$[0.5,0.75,1.0]$} \\
\hline \multirow{3}{*}{$\mathbf{V}_{\mathbf{k}}$} & VVL & Voltage Very Low & {$[0,0.25,0.5]$} \\
\hline & VL & Voltage Low & {$[0.25,0.5,0.75]$} \\
\hline & $\mathrm{VH}$ & Voltage High & {$[0.5,0.75,1.0]$} \\
\hline \multirow{3}{*}{$V_{k-1}$} & VVLP & $\begin{array}{l}\text { Voltage Very Low } \\
\text { at Previous condi- } \\
\text { tion }\end{array}$ & {$[0,0.25,0.5]$} \\
\hline & VLP & $\begin{array}{l}\text { Voltage Low Previ- } \\
\text { ous condition }\end{array}$ & {$[0.25,0.5,0.75]$} \\
\hline & VHP & $\begin{array}{l}\text { Voltage High Pre- } \\
\text { vious condition }\end{array}$ & {$[0.5,0.75,1.0]$} \\
\hline Output & MF & Description & Range \\
\hline \multirow{3}{*}{$V_{k+1}$} & OVL & Output Very Low & {$[0,0.25,0.5]$} \\
\hline & $\mathrm{OL}$ & Output Low & {$[0.25,0.5,0.75]$} \\
\hline & $\mathrm{OH}$ & Output High & {$[0.5,0.75,1.0]$} \\
\hline
\end{tabular}

Table1:2 Rules for fuzzy inference engine

\begin{tabular}{|l|c|c|c|c|c|}
\hline Rule & Input1 & Input2 & Input3 & Input4 & Output \\
\hline Rule1 & PL & PVPL & VVL & VLP & OVL \\
\hline Rule2 & PL & PVPL & VVL & VHP & OVL \\
\hline Rule3 & PL & PVPL & VL & VLP & OL \\
\hline Rule4 & PL & PVPL & VVL & VVLP & OH \\
\hline
\end{tabular}

\section{Simulation Results}

In this paper the standard cell SX-3190W of BP Solar Manufacturer [13]is considered. As it is shown in fig.4 a set of such PV cell are arranged in series and parallel combinations with partial shadings. The I-V and P-V Characteristics of PV cell are shown in 
fig.2 \& fig. 3 for different temperatures and varying irradiance. The short circuit current ISC vary linearly with Irradiance for the values are $1000 \mathrm{~W} / \mathrm{m}^{2}, 800 \mathrm{~W} / \mathrm{m}^{2}, 600 \mathrm{~W} / \mathrm{m}^{2}$. The open circuit voltage $V_{O C}$ vary with Temperature for the values are $25^{\circ} \mathrm{C}, 50^{\circ} \mathrm{C}$, $75^{\circ} \mathrm{C}$. The irradiation and temperature are the parameters of PV cell and vary with the environmental conditions. The proposed $\mathrm{P} \& \mathrm{O}$ based fuzzy controller block diagram is shown in fig. 10 . Inputs to the system are irradiation and temperature, and based on inputs and its characteristics the proposed controller is designed. Irrespective of variations in parameters, the output of PV cell is maintained constant. Fuzzy controller can adjust such that it can control and sets to get maximum output for various combinations of variation in parameters. In fig. 8 the proposed system is shown which consists of Shaded PV panel, P\&O based Fuzzy controller and boost converter. Shaded PV panel is combination of $9 \mathrm{PV}$ modules arranged into three parallel, each having $3 \mathrm{PV}$ modules connected in series. The output of Shaded PV panel is given to boost converter which is controlled by $\mathrm{P} \& \mathrm{O}$ fuzzy logic controller to get maximum output. Fuzzy takes voltage $\mathrm{V}$ and Power $\mathrm{P}$ as error signals. Along with 2 error signals their derivatives are 4 inputs to the Fuzzy controller as shown in fig.9. the proposed system is simulated for $700 \mathrm{~W} / \mathrm{m}^{2}$ irradiance and $27^{\circ} \mathrm{C}$, temperature. These two inputs are common for all 9 PV panels. Since they are connected in series parallel combinations their control is difficult but the proposed fuzzy controller could able to maintain constant output voltage of $198 \mathrm{~V}$ with maximum variation of $5 \%$ which is shown in fig. 12.

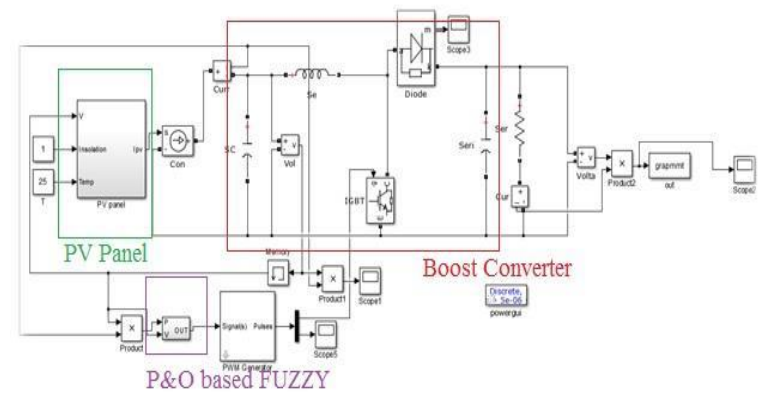

Fig. 10: Simulink diagram of proposed system

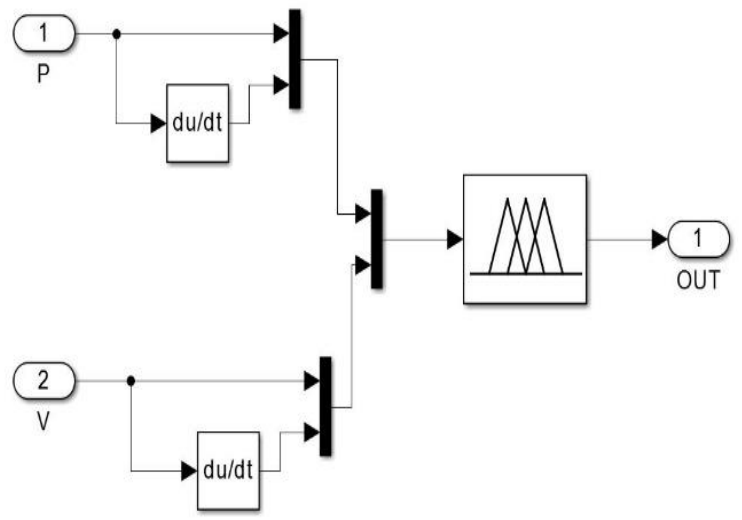

Fig.11: Fuzzy controller with P, V inputs

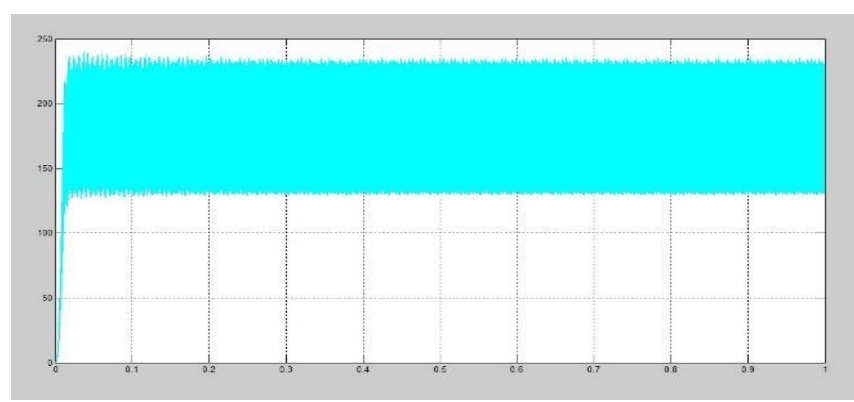

Fig.12: Output of proposed MPPT tracking system

\section{Conclusions}

A shaded PV array is formed using individual PV cells connected in series and parallel combinations. A MATLAB/SIMULINK model for shaded PV array is developed and simulated. Fuzzy rules are framed based on P\&O. based on these power converter switching is controlled and hence output power generated becomes constant, which is at maximum power point. The designed system adapt to Maximum power operating point to changes in PV system. It is observed that for shaded PV array, power output generated is more and constant when an MPPT with P\&O fuzzy is employed in the given system.

\section{References}

[1] Soheil Ahmadzadeh; Gholamreza Arab Markadeh, "Incremental conductance based MPPT using a high step-up Y-source DC-DC Converter", 2017 8th Power Electronics, Drive Systems \& Technologies Conference (PEDSTC).

[2] A. K. Gautam; S. P. Singh; J. P. Pandey; R. P. Payasi; Anuj Verma," Fuzzy logic based MPPT Technique for PhotoVoltaic energy conversion system", 2016 IEEE Uttar Pradesh Section International Conference on Electrical, Computer and Electronics Engineering (UPCON).

[3] Ramdan B. A. Koad; Ahmed Faheem Zobaa; Adel El-Shahat," A Novel MPPT Algorithm Based on Particle Swarm Optimization for Photovoltaic Systems", IEEE Transactions on Sustainable Energy, Year:2017, Volume: 8, Issue: 2, Pages: 468 - 476.

[4] Satyajit Mohanty; Bidyadhar Subudhi; Pravat Kumar Ray,"A grey wolf optimization based MPPT for PV system under changing insolation level", 2016 IEEE Students' Technology Symposium (TechSym), Pages:175 - 179 .

[5] J. A. Ramos-Hernanz; J. M. Lopez-Guede; E. Zulueta-Guerrero; Nicu Bizon; Fernando Oterino-Echavarri; Andres Larrea, "Study of the behavior of the incremental conductance algorithm for MPPT", 2016 8th International Conference on Electronics, Computers and Artificial Intelligence (ECAI).

[6] Ling Lu; Ping Liu, "Research and simulation on photovoltaic powersystem maximum power control", 2011 International Conference of Electrical and Control Engineering, 2011.

[7] Jubaer Ahmed, Zainal Salam,"A Modified P\&O Maximum Power Point Tracking Method with Reduced Steady-State Oscillation and Improved Tracking Efficiency", IEEE Transactions on Sustainable Energy, Volume: 7, 4, Oct. 2016.

[8] Jingxin Hu, Philipp Joebges, and Rik W. De Doncker "Maximum PowerPoint Tracking Control of a High Power DC-DC Converter for PV Integration in MVDC Distribution Grids", Applied Power Electronics Conference and Exposition (APEC), 2017 IEEE.

[9] Peter Wolfs, Quan Li, "A current-sensor-free incremental conductancesingle cell MPPT for high performance vehicle solar arrays", 37th IEEE Power Electronics Specialists Conference 2006.

[10] Ahmed A. S. Mohamed, Alberto Berzoy and Osama, "Design and Hardware Implementation of FL-MPPT Control of PV Systems Based on GA and Small-Signal Analysis", IEEE Transactions on Sustainable Energy, Vol. 8, No. 1, January 2017.

[11] Jyri Kivimaki, Sergei Kolesnik, Moshe Sitbon, and Alon Kuperman, Revisited Perturbation Frequency Design Guideline for Direct Fixed- Step Maximum Power Point Tracking Algorithms", IEEE Transactions on Industrial Electronics, Vol. 64, No. 6, June 2017.

[12] C. Bhanu Prasad, B.Raja Gopal Reddy, Soma Keerthi Sonam, Padamati Harika. "A fuzzy logic based MPPT method for solar power generation", IEEE 2017 International Conference on Intelligent Computing and Control Systems (ICICCS), 2017.

[13] BP Solar SX3190 solar panel module http://www.bp.com/en/global/corporate/customers/bp-solar- warranty.html. 